A and follistatin. Migration assay shows that IL-1-induced decrease on migration more prominent in indirect coculture and RASF monoculture than in direct coculture although in gap migration in the scratch assay was highest in direct coculture. Disclosure of Interests: None declared DOI: 10.1136/annrheumdis-2021-eular.271

\section{AB0045 THE RELATIONSHIP BETWEEN CD14 AND VIMENTIN- POSITIVE SYNOVIAL DENDRITIC-SHAPED CELLS AND SYNOVITIS IN RHEUMATOID ARTHRITIS}

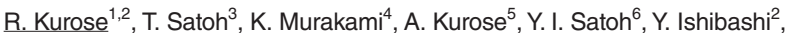
K. Ishida ${ }^{7}$, K. Ogasawara ${ }^{7}$, A. Morikawa ${ }^{8}$, T. Sawai ${ }^{9}{ }^{1}$ Hirosaki Memorial Hospital, Orthopedic Surgery, Hirosaki, Japan; ${ }^{2}$ Hirosaki University, Orthopedic Surgery, Hirosaki, Japan; ${ }^{3}$ Iwate Medical University, Pathology, Morioka, Japan; ${ }^{4}$ Iwate Medical University, Orthopaedic Surgery, Morioka, Japan; ${ }^{5}$ Hirosaki University, Pathology, Hirosaki, Japan; ${ }^{6}$ Iwate Medical University, Medical Education, Morioka, Japan; ${ }^{7}$ Iwate Medical University, Technical Support Center, Morioka, Japan; ${ }^{8}$ Hitachi High-Technologies Corporation, Electron Microscope Application Group, Hitachinaka, Japan; ${ }^{9}$ Tohoku University, Pathology, Sendai, Japan

Background: Inflammation in rheumatoid arthritis (RA) is caused by multiple cell types, including infiltrating inflammatory cells, such as lymphocytes, neutrophils, macrophages, and spindle-shaped fibroblasts. Especially, we are focusing on fibroblast-like synoviocytes (FLSs). In our previous study, we have reported that FLSs were positive for multiple markers including CD14, CD68 and HLA-DR, and were dendritic-shaped cells constituting nursing phenomenon between lymph or plasma cells. In addition, in our recent study, we found that CD14+FLSs were positive for vimentin (VIM), which is a marker for mesenchymal cells. There are still many issues to be discussed regarding CD14+VIM+ cells.

Objectives: To investigate the relationship between CD14+VIM+cells and the degree of synovitis in rheumatoid arthritis.

Methods: Synovial tissues collected from RA patients who underwent joint surgeries were prepared for this study. First, the proportions of CD14+ cells in RA synovial tissue and control were analyzed using flow cytometry and the concentrations of inflammatory cytokines released by CD14+ cells in RA synovial tissue and control were examined by ELISA. Next, the proportions of CD14+VIM+ cells in RA synovial tissue and control were examined immunohistologically and then we analyzed the results using image analysis software. Also, we statistically analyzed the relationship between the proportion of CD14+VIM+ cells, the degree of synovitis, and clinical data. Results: Results of flow cytometry showed that CD14+ cells were frequently observed in RA synovial tissue than control. Cultured CD14+ cells released more inflammatory cytokines than cultured CD14- cells. Also, results of immunohistological staining showed that many CD14+VIM+ cells were observed in RA synovial tissue than in control. The proportion of CD14+VIM+ cells was correlated with Krenn synovitis score. High proportion cases significantly showed high level of CRP and MMP-3.

Conclusion: $\mathrm{CD} 14+\mathrm{VIM}+$ cells might be involved in the mechanism of chronic immunological inflammation in RA and the proportion of these cells might influence the clinical data.

REFERENCES

[1] Ochi T, Yoshikawa H, Toyosaki-Maeda T, Lipsky PE. Mesenchymal stromal cells. Nurse-like cells reside in thesynovial tissue and bone marrow in rheumatoid arthritis. Arthritis Research\&Therapy 2007; 9(1): 201.

[2] Ochi T, Sawai T, Murakami K, Kamataki A, Uzuki M, Tomita T, et al. Nurselike cells in rheumatoid arthritis: Formation of survival niches cooperating between the cell types. Mod Rheum 2018; 29: 1-5.

[3] Krenn V, Morawietz L, Burmester GR, Kinne RW, Muller-Ladner U, Muller B, Haupl T. Synovitis score: discrimination between chronic low-grade and high-grade synovitis. Histopathology 2006; 49: 358-64.

Disclosure of Interests: None declared

DOI: 10.1136/annrheumdis-2021-eular.428

\section{AB0046 \\ THE EXPRESSION AND CLINICAL SIGNIFICANCE OF TAM RECEPTOR TYROSINE KINASE ON MONOCYTE SUBSETS IN RHEUMATOID ARTHRITIS}

J. Xue ${ }^{1}$, L. Xu ${ }^{1}$, F. Hu ${ }^{1}$, Y. Su ${ }^{1}{ }^{1}$ Peking University People's Hospital, Department of Rheumatology and Immunology, Beijing, China

Background: The TAM receptor tyrosine kinases (Tyro3/Axl/Mer TK) are a subfamily of receptor tyrosine kinases, the role of which in autoimmune diseases such as systemic lupus erythematosus has been well explored, while their functions in rheumatoid arthritis (RA) remain largely unknown [1].

Objectives: The study aimed to investigate the expression and clinical significance of Tyro3, AxI and MerTK on monocyte subsets in rheumatoid arthritis (RA). Methods: The expression of Tyro3, Axl and MerTK on CD14+ monocytes, nonclassical monocytes ( $\mathrm{NCM}, \mathrm{CD} 14^{+} \mathrm{CD} 16^{++}$), intermediate monocytes (IM, $\left.\mathrm{CD}_{14}{ }^{++} \mathrm{CD} 16^{+}\right)$, and classical monocytes $\left(\mathrm{CM}, \mathrm{CD} 14^{++} \mathrm{CD} 16^{-}\right)$were evaluated in peripheral blood of RA by flow cytometry and qPCR. And the correlation between the expression of Tyro3TK and MerTK on NCM, IM, and CM with RA patient clinical feature were further analyzed.

Results: The results revealed that the expression of Tyro3TK on CD14+ monocytes was significantly upregulated in RA patients $(F=9.18, P<0.0001)$, while there was no significant difference of the expression MerTK on $\mathrm{HC}, \mathrm{OA}$, and RA, and the expression of AxITK was minimal (Fig 1). The expression of Tyro3TK on $\mathrm{CM}$ was significantly upregulated in RA patients as compared with $\mathrm{HC}$ and osteoarthritis $(O A)$ patients $(P<0.05$, Fig $2-3)$, and positively correlated with the disease manifestations, such as swollen joint count (SJC), tender joint count (TJC) and the disease activity score (Fig 4)
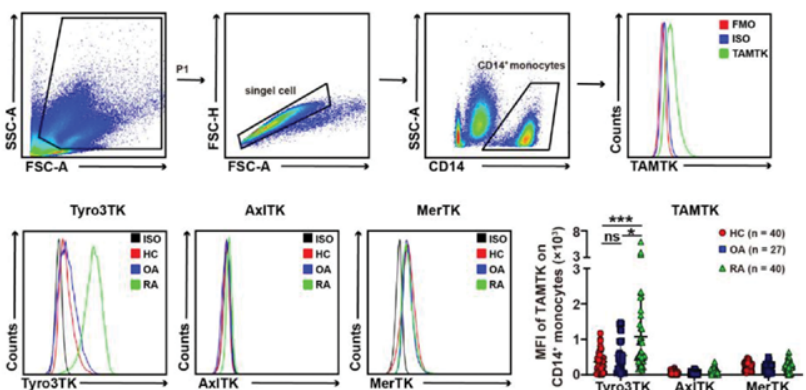

Figure 1. The expression of Tyro3, Axl and MerTK on CD14+ monocytes is increased in RA. (a) Gating strategy for flow cytometry of Tyro3, Axl and MerTK on CD14+ monocytes. (b) The expression of Tyro3, Axl and MerTK on CD14+ monocytes were compared between $\mathrm{HC}(\mathrm{n}=40), \mathrm{OA}(\mathrm{n}=27)$, and RA patients $(\mathrm{n}=40) .{ }^{*} P<0.05,{ }^{\star \star} P<0.01, \mathrm{~ns}$, not significant.
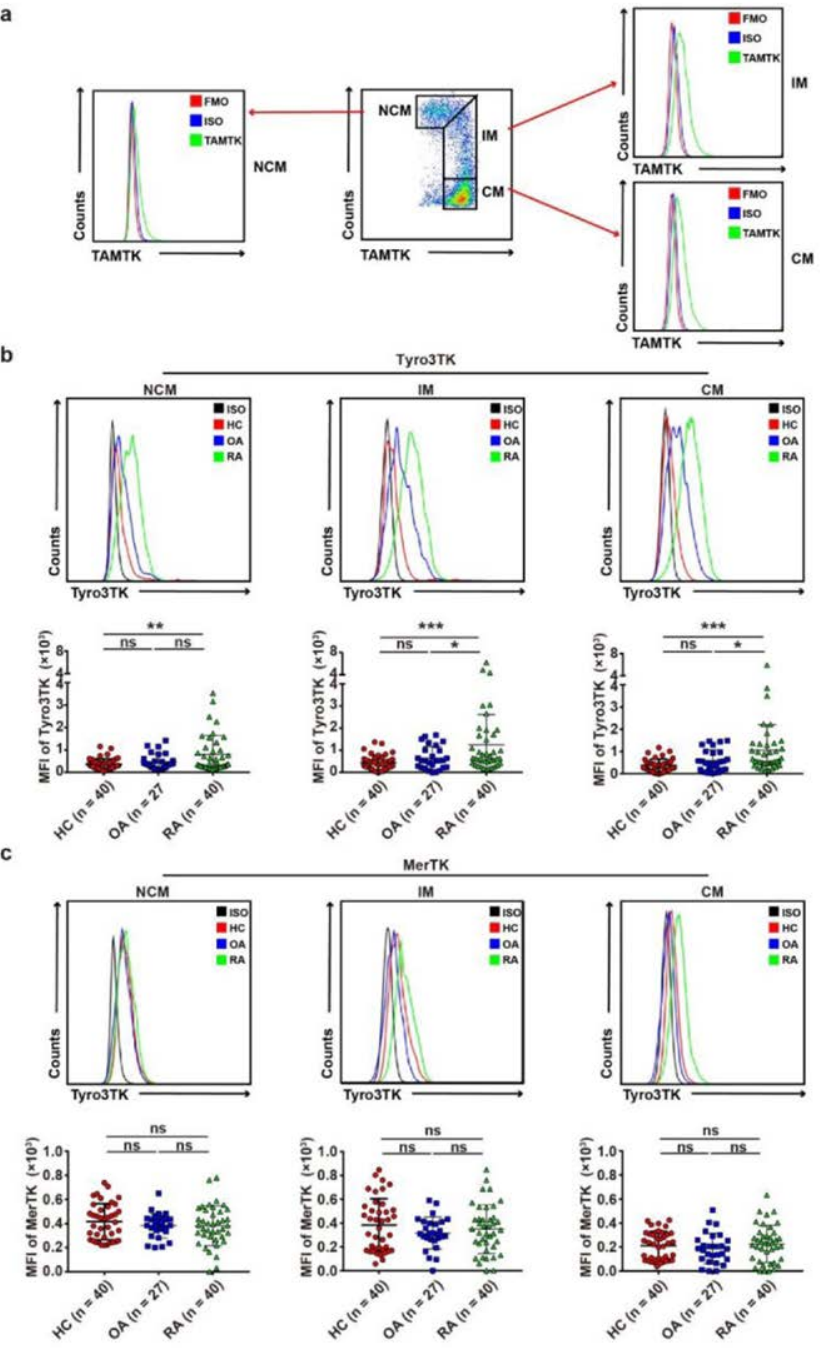

Figure 2. The expression of Tyro3TK on IM and CM were increased in RA. (a) Gating strategy for flow cytometry of TAMTK on monocyte subsets. The expression of (b) Tyro3TK and (c) MerTK on NCM, IM, and CM were compared between HC $(n=40), O A(n=27)$, and RA patients $(\mathrm{n}=40)$. ${ }^{\star} \mathrm{P}<0.05$, ${ }^{\star *} P<0.01$, ${ }^{\star \star *} P<0.001$, ns, not significant. 

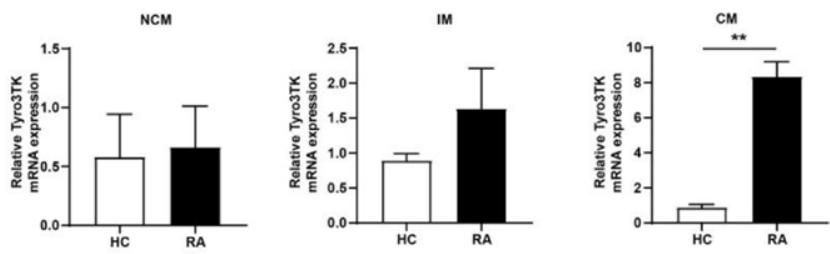

b
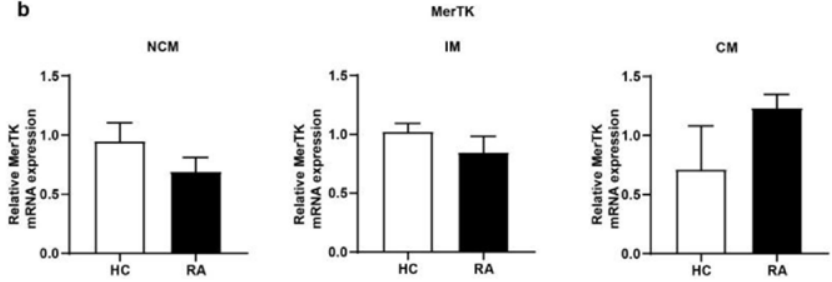

Figure 3. The mRNA expression of Tyro3TK on CM is increased in RA. (a) The mRNA expression of Tyro3TK on NCM, IM, and CM in HC $(n=3)$ and RA $(n=3)$ patients. (b) The mRNA expression of MerTK on NCM, IM, and CM in $\mathrm{HC}(\mathrm{n}=3)$ and RA $(\mathrm{n}=3)$ patients. ${ }^{* *} P$ $<0.01$.

Conclusion: These findings indicate that Tyro3TK on CM was elevated in RA patients and correlated positively with disease activity, which may serves as an important participant in RA pathogenesis.

REFERENCES:

[1] Rothlin CV, Lemke G, TAM receptor signaling and autoimmune disease. Curr Opin Immunol, 2010. 22(6): p. 740-6.

Footnotes: The study was supported by grants from the National Natural Science Foundation of China (81671609 and 81871290 to Dr. Y. Su, 82001718 to Dr. L. Xu), the Beijing Science and Technology Planning Project (Z191100006619111 to Dr. Y. Su), the Beijing Municipal Natural Science Foundation (7194329 to Dr. L. Xu).
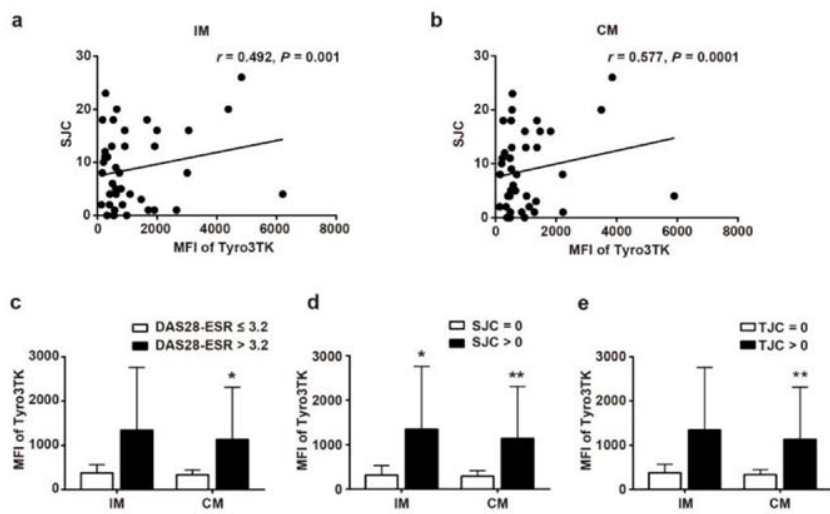

Figure 4. Correlation analysis of Tyro3TK on IM and CM with RA patient clinical manifestations. The associations of Tyro3TK on IM $\left(r=0.492,{ }^{\star} P=0.001\right)$ (a) and $\mathrm{CM}\left(\mathrm{r}=0.577,{ }^{\star} P=\right.$ 0.0001 ) (b) with RA patient swollen joint counts (SJC) were analyzed, respectively. The expression of Tyro3TK on IM and CM were also compared between different RA patient groups: (c) RA with high disease activity (DAS28-ESR $>3.2$ ) and non-high disease activity (DAS28-ESR $\leq$ 3.2), (d) RA with and without swollen joints, (e) tender joints. ${ }^{\star} P<0.05,{ }^{\star \star} P<0.01$

Disclosure of Interests: None declared DOI: 10.1136/annrheumdis-2021-eular.636

\section{AB0047 CLINICAL AND RADIOLOGICAL CHARACTERISTICS AND TREATMENTS OF A COHORT OF PATIENTS WITH RHEUMATOID ARTHRITIS AND DIFFUSE INTERSTICIAL PULMONARY DISEASE FOLLOWED AT THE VIRGEN MACARENA UNIVERSITY HOSPITAL}

P. Muñoz Reinoso ${ }^{1}$, F. J. Toyos Sáenz de Miera ${ }^{1}$, D. Ruiz-Montesinos ${ }^{1}$, I. García Hernández ${ }^{1}$, P. Guerrero Zamora ${ }^{2}$, J. J. Pérez Venegas ${ }^{1} .{ }^{1}$ Hospital Universitario Virgen Macarena, Reumatología, Sevilla, Spain; ${ }^{2}$ Hospital Universitario Virgen Macarena, Neumología, Sevilla, Spain

Background: Diffuse interstitial lung disease (ILD) is an extra-articular manifestation of rheumatoid arthritis $(R A)^{1,2}$. The most common pattern is the usual interstitial pneumonia (UIP), conditioning a worse prognosis ${ }^{3}$.
Objectives: To describe epidemiological, clinical, and radiological characteristics and treatment used in a cohort of patients diagnosed with RA and ILD.

Methods: Retrospective descriptive study, including patients with a diagnosis of RA and ILD, reviewed in the Rheumatology and Pneumology consultations of the Virgen Macarena University Hospital, from 2010 to 2019. Data obtained from medical records are analyzed. SPSS statistical software is used.

Results: 26 patients were included, 18 women (69.2\%). Median age at diagnosis of ILD was 62 years (53-73). Twelve patients (46.6\%) used to smoke. The mean time from RA diagnosis to ILD diagnosis was 79 months (8-264). The RF was positive in $91.3 \%$ cases $(21)$ and $87 \%$ of them (20) were ACPA positive. Fourteen patients $(53.8 \%)$ had erosions and $3(11.5 \%)$ had an associated Sjögren's Syndrome. When ILD was diagnosed, the RA activity by DAS28PCR was moderate (3.28; 2.34-3.28) and 13 patients $(54.1 \%)$ suffered from dyspnea. The mean value of FVC and DLCO in the first assessment was $84 \%$ (63-108) and 71.7\% (64-86), respectively. The most frequent radiological pattern of ILD was NINE in 15 patients $(57.7 \%), 6$ of them $(23.1 \%)$ had UIP and $5(19.3 \%)$ presented other patterns. Prior to ILD diagnosis, $24(92.3 \%)$ patients received oral glucocorticoids, 18 (69.2\%) cases started treatment with c-DMARD and 11 (42.3\%) of them with b-DMARD the most widely used were methotrexate (MTX) in 17 patients $(65.4 \%)$ and anti$\mathrm{TNF} \alpha$ in 10 (38.5\%). After diagnosis, treatment was changed to 12 patients $(46.6 \%)$; the most used DMARD was leflunomide, in $11(42.3 \%)$, MTX was maintained in 7 patients $(26.9 \%)$; the number of anti-TNF $\alpha$ used decreased to 4 cases $(15.4 \%)$, using instead drugs such as rituximab $5(19.2 \%)$, abatacept $3(11.5 \%)$ baricitinib $2(7.7 \%)$ and anti-IL6 2 (7, 7\%). During follow-up, 11 cases $(57.9 \%)$ remained radiologically stable. A slight deterioration in DLCO was observed $(66 \%$; 51-80) and there was one death due to lung disease (UIP).

Conclusion: In this study, the most frequent radiological pattern was NINE. Half of the patients used to smoke. At the diagnosis of ILD (at ILD diagnosis), dyspnea was the most relevant clinical symptom, with a slight deterioration in the? respiratory function tests. This represented a change in the therapeutic strategy. REFERENCES:

[1] Olson AL, Swigris JJ, Sprunger DB, et al. Rheumatoid arthritis-interstitial lung disease-associated mortality. Am J Respir Crit Care Med. 2011;183:372-78.

[2] Fragoulis GE, Nikiphorou E, Larsen J, Korsten P and Conway R. Methotrexate-Associated Pneumonitis and Rheumatoid Arthritis-Interstitial Lung Disease: Current Concepts for the Diagnosis and Treatment. Front. Med. 2019;6:238

[3] Tanaka N, Kim JS, Newell JD, et al. Rheumatoid arthritis-related lung diseases: CT findings. Radiology. 2004;232:81-91.

Disclosure of Interests: None declared

DOI: 10.1136/annrheumdis-2021-eular.1413

\section{AB0048 \\ ENZYMATIC PATTERN OF CIRCULATING PRO- AND ANTIOXIDANT ENZYMES IN RHEUMATOID ARTHRITIS PATIENTS}

S. Bedina ${ }^{1}$, E. Mozgovaya ${ }^{1}$, A. Trofimenko ${ }^{1}$, S. Spitsina ${ }^{1}$, M. Mamus ${ }^{1}$.

${ }^{1}$ Research Institute of Clinical and Experimental Rheumatology named after A.B. Zborovsky, Clinical Biochemistry Lab, Volgograd, Russian Federation

Background: Rheumatoid arthritis (RA) is an autoimmune rheumatic disease of unknown etiology characterized by chronic erosive arthritis and systemic organ involvement resulting in early disability and shorter life expectancy. Neutrophils are suggested to play a substantial role in the induction and promotion of autoimmune inflammation in RA. This ability can be based on newly discovered feature of neutrophils to release neutrophil extracellular traps (NETs) during specific type cell death called NETosis. Hyperproduction of reactive oxygen species (ROS) is one of the factors promoting NETs production. With this background, the study of pro- and antioxidant enzymatic activities in RA patients can be of great interest. Objectives: To assess plasma activities of essential prooxidant and antioxidant enzymes in RA patients.

Methods: The research was carried out in agreement with the WMA Declaration of Helsinki principles. 71 RA patients (46 women and 25 men) were enrolled in the study. The diagnosis was verified using ACR/EULAR criteria (2010). RA activity was measured using the Disease Activity Score of 28 joints (DAS28). 30 healthy persons comprise control group. Plasma xanthine oxidase (XO; EC 1.17.3.2), xanthine dehydrogenase $(X D H ; E C$ 1.17.1.4) and superoxide dismutase (SOD; EC 1.15.1.1) activities were measured using spectrophotometric technique. XO and XDG activities were expressed as $\mathrm{nmol} / \mathrm{ml} / \mathrm{min}$, SOD activity - as units of action. Statistical analysis was performed using Statistica 6.0 software package. Differences were considered significant when $p<0.05$. Reference ranges were calculated as means $\pm 2 S D$.

Results: Mean age of patients was $43.2 \pm 3.6$ years, mean RA duration was $11.9 \pm 2.6$ years. $24(33.8 \%)$ RA patients had low disease activity, and $6(8.5 \%)$ patients had high one. Extra-articular manifestations were found in $30(42.2 \%)$ patients. $30 \%$ of them had cardiovascular involvement, $23.3 \%$ - pulmonary lesions, and $23.3 \%$ had renal involvement. Reference ranges for XO, XDG, and SOD activities were 2.28-5.12 nmol $/ \mathrm{min} / \mathrm{ml}, 3,96-7,24 \mathrm{nmol} / \mathrm{min} / \mathrm{ml}$, and 3,136,58 units, respectively. We examined activities of these enzymes in circulation 